\title{
A METHOD FOR DETERMINING STRESSES IN A NON- ROTATING PROPELLER BLADE VIBRATING WITH A NATURAL FREQUENCY
}

\author{
By Walter Ramberg, Paul S. Ballif, and Mack J. West
}

ABSTRACT

Propeller failures in flight generally have the appearance of fatigue fractures. This points to resonant vibrations setting up excessive alternating stresses as a probable cause of failure. The present paper describes a method for measuring and for calculating such alternating stresses for the case of a nonrotating propeller vibrating in resonance with an alternating torque applied to its shaft. A complete picture of the stress distribution in such a propeller was obtained by measuring the longitudinal and transverse strain amplitudes at various points, and calculating the stresses from these measurements, assuming a condition of plane stress at the surface of the blade. Stress distributions were obtained for a duralumin blade vibrating with its fundamental mode and also for the same blade vibrating with its second harmonic mode (with a node near the tip). The measured stress distributions and frequencies for the two modes were checked by the stresses and frequencies calculated from the theory of vibiating beams of variable section. The effect of restraint at the hub on frequency and on stress distribution was also investigated theoretically, and it was found that the degree of restraint at the hub affected the stress distribution very little, but that it had considerable effect on the natural frequency. A further check on the measurements was made by noting that artificially produced fatigue failures in eight nonrotating blades vibrating with their fundamental mode occurred in each case at a section where the stresses were within a few percent of the maximum stress measured.

\section{CONTENTS}

I. Statement of problem

II. Experimental procedure _...

1. Excitation of vibration

2. Amplitude of vibration

3. Measurement of strain _...

III. Analysis of experimental results

1. Stress distribution for fundamental mode . . .

2. Stress distribution for second harmonic mode

IV. Theoretical analysis of stress distribution in a propeller blade vibrating without rotation.

1. Method

(a) Equation of motion of blade... 197

(b) Numerical solution of equations of motion

(c) Calculation of stress

2. Fundamental mode of fixed-free propeller blade

3. Second harmonic $\mathrm{m}$ )de of fixed-free propeller blade_....... 207

4. Fundamental mode of free-free propeller blade . . .

V. Comparison of measured and theoretical values_.............. 212

1. Comparison of stress distribution

2. Comparison of frequencies

VI. Preliminary results of fatigue tests on nonrotating propeller blades._. 212 VII. Conclusions. 


\section{STATEMENT OF PROBLEM}

An investigation of the vibration of aircraft propeller blades, having as its ultimate aim the diagnosis of the failure of propellers in flight, is being carried out at the National Bureau of Standards. Failures occur in most cases either close to the hub or a few inches from the tip of the blade. They have the characteristic appearance of fatigue fractures, thus pointing to alternating stresses as the cause. The source of such alternating stresses is not definitely known; but it is known that alternating stresses occur whenever a periodically varying torque is applied to the propeller shaft or whenever periodic impulses are applied to the blades themselves. It is also known that periodic forces in resonance with one of the natural frequencies of the propellershaft system may set up propeller vibrations of relatively large amplitude.

It seemed logical to start the investigation with propellers vibrating without rotation in order to get a clear picture of their behavior under these relatively simple conditions before going to the more complex ones of the rotating propeller. There were good reasons to think that such a preliminary investigation would result in the development of a technique and in the assembly of data that would later be of value in considering propellers in flight. For example, it has been demonstrated that the natural frequency of the fundamental mode of a rotating propeller can be estimated with some degree of accuracy in a simple manner from the natural frequencies without rotation. ${ }^{1}$

Considerations similar to these suggested the following line of attack on the problem:

1. Develop a method for applying periodic impulses of controllable frequency and amplitude to nonrotating propeller blades so as to set up resonant vibrations of sufficient amplitude to cause failure, if possible.

2. Develop a method for measuring the stresses set up in the vibrating blade and, if possible, obtain values at the points of failure for the stresses just preceding failure.

3 . Extend these methods to propeller blades in rotation.

The present paper will deal principally with the second part of the research program, that is, with a description of a method developed for determining the stresses in a nonrotating propeller blade vibrating with a natural frequency.

\section{EXPERIMENTAL PROCEDURE}

\section{EXCITATION OF VIBRATION}

The first part of the research program has already been described in an article by L. B. Tuckerman, H. L. Dryden, and H. B. Brooks. ${ }^{2}$ The application of the method there described to the present problem will be clear after an examination of the photograph, figure 1. G in this figure is a 27 -hp motor-generator set which is able to supply nearly sinusoidal alternating current in a range of frequencies from 10 to $180 \mathrm{cycles} / \mathrm{second}$. This alternating current is fed into the armature of the 15-hp motor, $\mathrm{M}$; the field coils of this motor are excited by direct current so that sinusoidal impulses of torque are set up in the shaft of the motor with an amplitude that is nearly proportional (up to saturation of the magnetic field) to the product of the field current

\footnotetext{
1 F. Liebers. Jahrb. Deut. Versuchsanstalt Luftfahrt 2, 20-28 (1932).
}

2 BS J. Research 10, 659 (1933) R P556. 


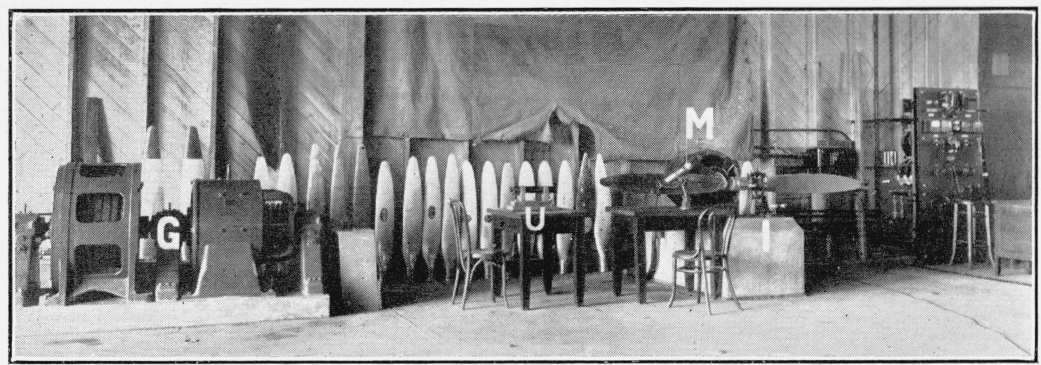

Figure 1.-Propeller vibration apparatus.

Over-all view, final set up (G, 27-hp variable-frequency motor-generator set; U, telescope for observing tip amplitude; M, 15-hp direct-current motor; I, outboard bearing for motor shaft).

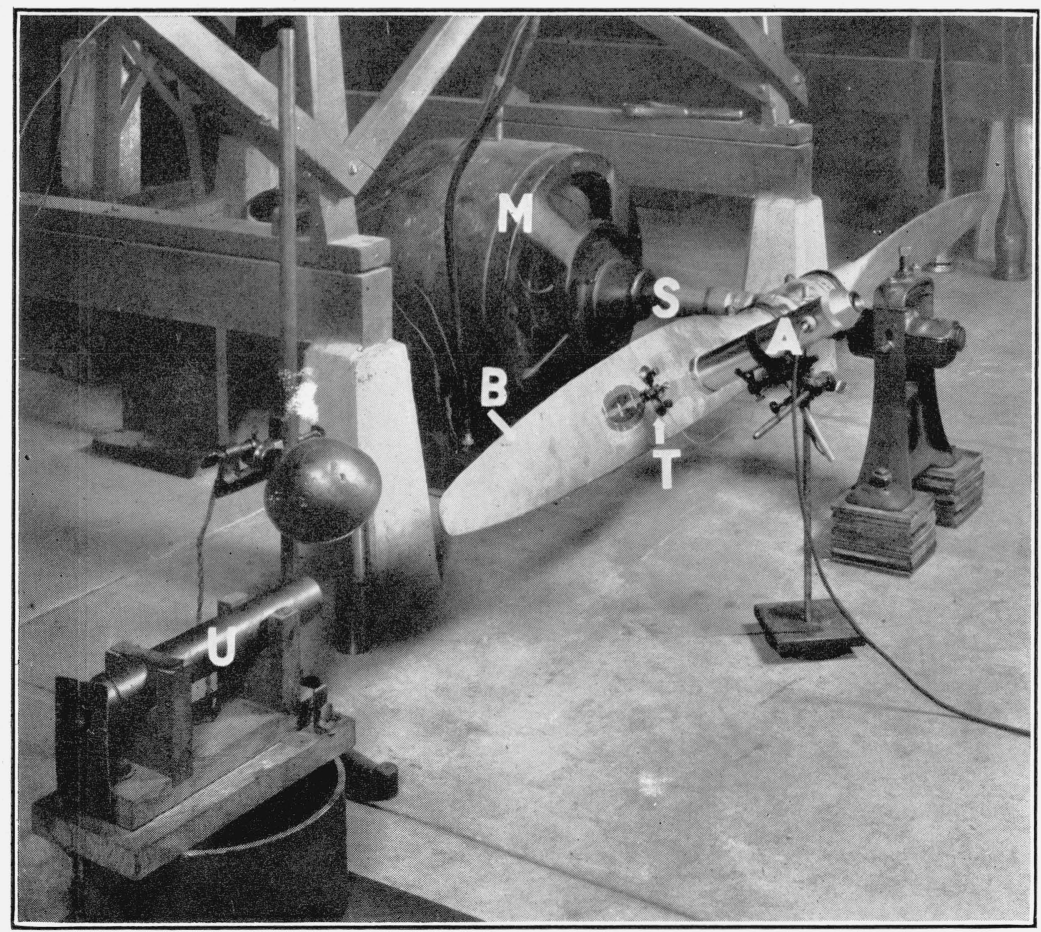

FigURE 2.-Propeller vibration apparatus, close up.

Initial set up (U, telescope for observing tip amplitude; M, 71/2-hp direct-current motor; S, motor shaft; B, propeller blade; T, Tuckerman optical strain gage; A, Tuckerman autocollimator). 
and the armature current, and with a frequency equal to the frequency of the armature current. These torsional impulses are transmitted to the propeller through the shaft of the motor. The stand, I, in front of the propeller carries a 4 -screw bearing for holding the forward tip of the shaft. This bearing was used to prevent excessive vibration of the shaft as a cantilever beam heavily loaded at the end.

\section{AMPLITUDE OF VIBRATION}

The amplitude of vibration of the propeller blade was observed by measuring with the telescope, $\mathrm{U}$, the motion of an illuminated point at one of the two tips (figs. 1, 2;2 is an earlier assembly). The telescope had a special reticule on which a sheet of cross-section paper had been photographed. The motion of the vibrating point appears as a bright line magnified 10 times on the cross-section paper.

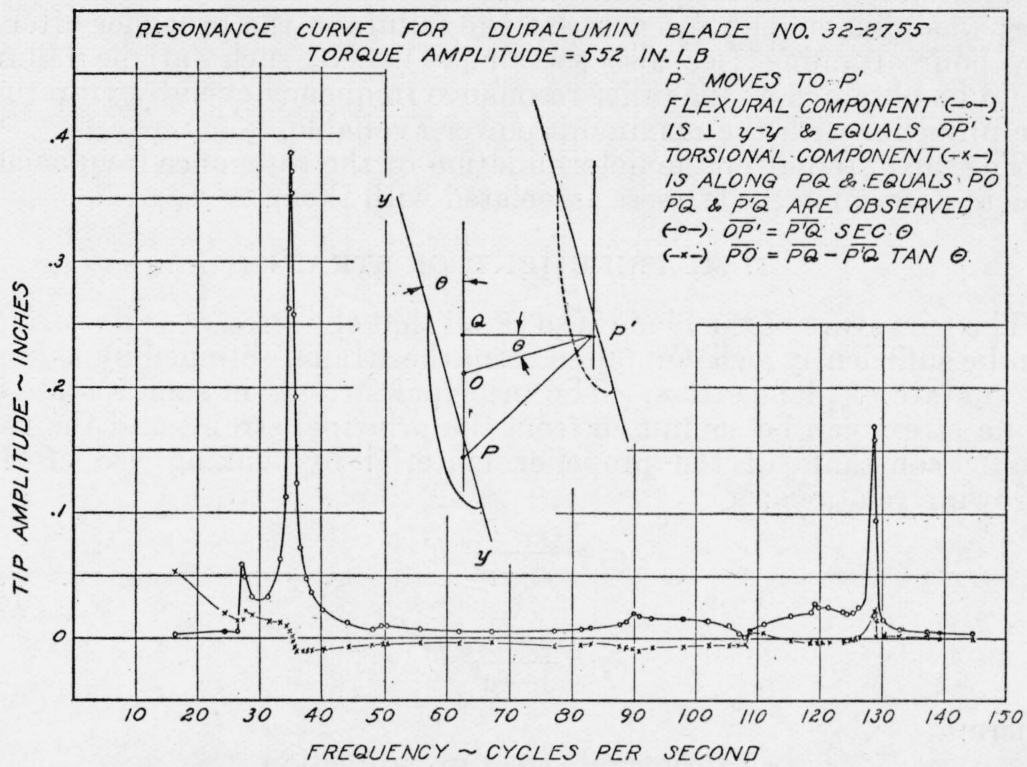

Figure 3.-Resonance curve for a duralumin blade.

The amplitude can be measured to about $0.01 \mathrm{in}$. by reading the end points of this line. The plane of motion follows directly from the angle which the bright line makes with the axes of the cross-section paper. The magnitude of the motion may be regarded as the vector sum of two motions, one in the plane of rotation of the propeller (OP, fig. 3), the other normal to the plane of the blade at the tip $\left(\mathrm{OP}^{\prime}\right.$, fig. 3). The components $\mathrm{OP}, \mathrm{OP}^{\prime}$ are obtained directly from the components of motion, $\mathrm{PQ}$ in the plane of rotation of the blade and $\mathrm{QP}^{\prime}$ normal to that plane, by setting one axis of the cross-section paper parallel to the plane of rotation of the blade. It is then easily shown from the sketch in figure 3 that

$$
\begin{aligned}
& \mathrm{OP}=\mathrm{PQ}-\mathrm{P}^{\prime} \mathrm{Q} \tan \theta \\
& \mathrm{OP}^{\prime}=\mathrm{QP}^{\prime} \sec \theta
\end{aligned}
$$

where $\theta$ is the angle which the plane of the blade at the tip makes with the plane of rotation of the propeller. 
In this way the torsional motion OP of the shaft may be separated from the flexural motion $\mathrm{OP}^{\prime}$ of the blade, and separate resonance curves obtained for each motion. Figure 3 shows the result for a duralumin blade of common design (no. 32-2755). The amplitude at the tip for an armature current of $15.0 \mathrm{amp}$ corresponding to a torque amplitude of 552 in-lb is here plotted against the frequency for a range of frequencies from about 15 to 140 cycles/sec. Two resonance peaks are noticeable; the first one about 35 cycles/sec corresponding to a vibration of each blade similar to a cantilever beam fixed at one end, and the second one around 130 cycles/sec corresponding to a vibration of the blade as a cantilever beam with a node near the tip of the blade. It is seen at once from figure 3 that by far the largest amplitudes were observed when the propeller was excited with its fundamental cantilever beam frequency at around 35 cycles/sec. This amplitude could in fact be increased to a value that was high enough to cause fatigue failure in the propeller after a few hours running (see also section VI). No such fatigue failure could be obtained a' the other resonance frequency even by vibrating the propeller with the maximum power available.

The next step after the determination of the resonance frequencies was to determine the stresses associated with them.

\section{MEASUREMENT OF STRAIN}

The curvature of the blade is so small that the stresses at its surface can be sufficiently well computed from the strains obtained by assuming a state of plane stress. The principal stresses in such a state of plane stress can be computed from the principal strains and the two elastic constants of the propeller material by making use of the following relations: ${ }^{3}$

$$
\begin{gathered}
\sigma_{x}=\frac{\epsilon_{x}+\mu \epsilon_{y}}{1-\mu^{2}} E \\
\sigma_{v}=\frac{\epsilon_{v}+\mu \epsilon_{x}}{1-\mu^{2}} E
\end{gathered}
$$

where:

$\sigma_{x}=$ principal stress in $x$-direction.

$\sigma_{y}=$ principal stress in $y$-direction.

$\epsilon_{x}=$ principal strain in $x$-direction.

$\epsilon_{y}=$ principal strain in $y$-direction.

$E=$ Young's modulus of material.

$\mu=$ Poisson's ratio of material.

The principal strains $\epsilon_{x}, \epsilon_{y}$ may be considered as the semiaxes of a strain ellipse. The determination of this strain ellipse at a given point on the propeller blade requires the observation of strains in four different directions about the point. Three would suffice if we were dealing with static strain; one more is needed if the strains vary as a simple harmonic motion, whose amplitude alone can be measured, in order to determine the phase relation between $\epsilon_{x}$ and $\epsilon_{y}$. It was found experimentally that the motion of any point on the propeller blade when vibrating in resonance with its fundamental frequency was close to such a simple sine motion.

\footnotetext{
${ }^{3}$ S. Timoshenko. Strength of Materials. 1, 58. (D. Van Nostrand Co., New York, 1930.)
} 
Knowing the strains in any four directions about a point, the principal strains can be derived by a geometrical construction. ${ }^{4}$

The experimental procedure for obtaining the strain readings was as follows. A 2-inch Tuckerman optical strain gage (T, fig. 2) was held firmly against the blade surface by two vacuum cups, with its knife-edge and lozenge each 1 inch from the point studied. The blade was caused to vibrate at its resonance frequency and the amplitude at the tip was observed through the telescope, $U$, in the manner described above. The average strain amplitude over a 2 -inch span was read off directly by using the calibrated Tuckerman autocollimator, A, with the "dumbbell" reticule especially designed for the measurement of dynamic strains. ${ }^{5}$

It should be noted in this connection that the usual $30^{\circ}$ knife-edge was replaced by a $90^{\circ} \mathrm{knife}-\mathrm{edge}$ to minimize the error introduced by the bending of the knifeedges by inertia forces resisting the acceleration of the gage in its simple harmonic motion. It can be shown theoretically that the error from this source may be eliminated by reading the gage in one position, turning it $180^{\circ}$, reading it again, and taking the average of the two readings, provided the deflection due to inertia forces is smaller than the extension to be measured. This was verified experimentally by noting that the average of two strain readings at a given point taken with a $30^{\circ}$ knife-edge was in close agreement with the average obtained with the $90^{\circ} \mathrm{knife}-$ edge, although the differ-

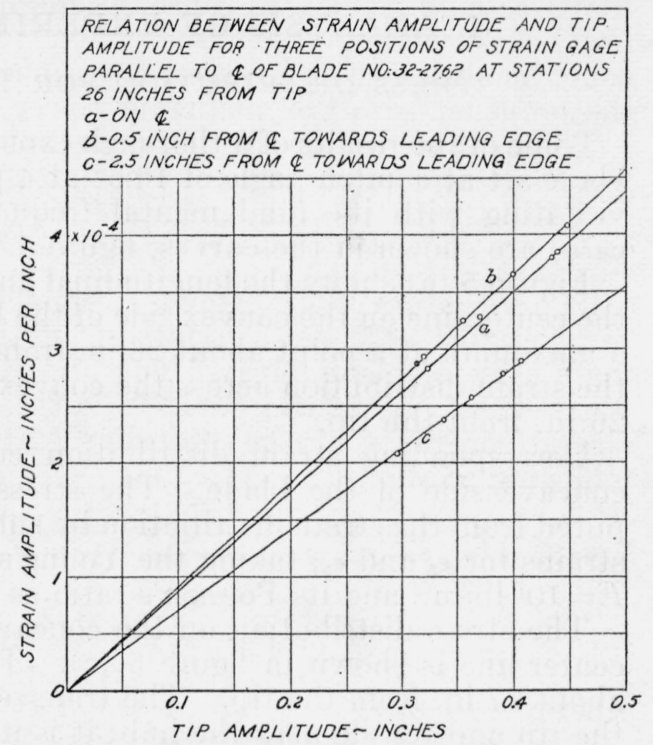

Figure 4.--Relation between strain amplitude and tip amplitude.

ence between individual

readings (about 40 percent for the $30^{\circ}$ knife-edge) was about five times as large in the first case as in the second. The difference in the two readings using the heavy knife-edge was negligible for most points on a blade vibrating with its fundamental frequency.

The strain for a given position of the strain gage was obtained for at least four different tip amplitudes ranging from 0.05 to 0.5 in., the tip amplitudes ${ }^{6}$ being increased by increasing the armature current of the driving motor. It was found that the strain was proportional to the tip deflection, the observations lying close to a straight line when strain amplitude was plotted against tip amplitude (see fig. 4). The slope of the straight line faired through the observed points gives the strain amplitude for 1 in. tip amplitude. The propor-

W. R. Osgood and R. G. Sturm. BS J. Research 10, 685 (1933) RP559.

s George K. Burgess. Paper 335, pp. 33-36. World Eng. Cong., Tokyo (Nov. 1929).

The term amplitude as used here designates one-half the total excursion of the vibrating mark. 
tionality between strain amplitude and tip amplitude was verified at a point near the hub up to a tip amplitude of about $1 \frac{112}{2}$ in.; that is, up to amplitudes approaching those at which fatigue failure occurred.

Strains per inch of tip amplitude were determined in this manner in four directions about several points, and the principal strains were computed, using the method described by Osgood and Sturm. ${ }^{7}$ The two principal strains were found parallel and at right angles, respectively, to an approximate center line which was constructed by connecting points that were equidistant from the leading and the trailing edge of the blade. Hence it was thought sufficient to take :wo gage readings for each point studied, one parallel to this center line and the other normal to it, and to assume that the strains thus observed were equal to the principal strains and could, therefore, be silhstituted in the expressions eq 2 for the principal stresses.

\section{ANALYSIS OF EXPERIMENTAL RESULTS}

\section{- ITRESS DISTRIBUTION FOR FUNDAMENTAL MODE}

4 me of the results of a thorough exploration of a 47.6 in. duralumin H, re set at a pitch angle of $19.6^{\circ}$ at a point $5.5 \mathrm{in}$. from the tip and vinating with its fundamental frequency (34.8 cycles/sec in this ense) are shown in the curves, figure 5 .

Figure 5 (a) shows the longitudinal and the transverse strains along the center line on the convex side of the blade. The strain $\epsilon_{x}$ becomes a maximum at a point about 26 in. from the tip. Figure 5 (b) shows the strain distribution across the convex side of the blade at a section 26 in. from the tip.

Corresponding strain distribution curves were obtained for the concave side of the blade. The stress distribution was then computed from the strain distribution by substituting in eq 2 the observed strains for $\epsilon_{x}$ and $\epsilon_{y}$, taking the Young's modulus of the material as $E=10^{7} \mathrm{lb} / \mathrm{in}^{2}$ and its Poisson's ratio as 0.3 .

The stress distribution on the concave side of the blade along the center line is shown in figure 5 (c). The stress is largest at a point about $27 \mathrm{in}$. from the tip. The transverse stress is compressive near the tip and tensile near the hub; it is in no case more than one-third the longitudinal stress. This behavior may be explained qualitatively from the shape of the blade, remembering that the direction of the principal longitudinal stress near the edges of the blade must be nearly parallel to the respective edges. The edges tend to converge towards the tip, and the corresponding stresses make an angle with each other, thus throwing the material between them into compression in a transverse direction.

Figure 5 (d) shows the stress distribution on the concave side of the blade at a section $26 \mathrm{in}$. from the tip. The transverse stress is nearly 0 , as it would be for a rectangular beam. The longitudinal stress increases steadily in passing from the trailing edge toward the leading edge up to a point near the leading edge; this behavior may be explained by the change in thickness of section and consequent change in the distance from the neutral surface to the extreme fiber in proceeding from one edge of the blade to the other.

\footnotetext{
7 W. R. Osgood and R. G. Sturm. BS J. Research 10, 685 (1933) RP559.
} 
The stress distribution along the centerline on the convex side of the blade is shown in figure 5 (e). This is of the same general nature as the corresponding stress distribution on the concave side (fig. 5 (c)).
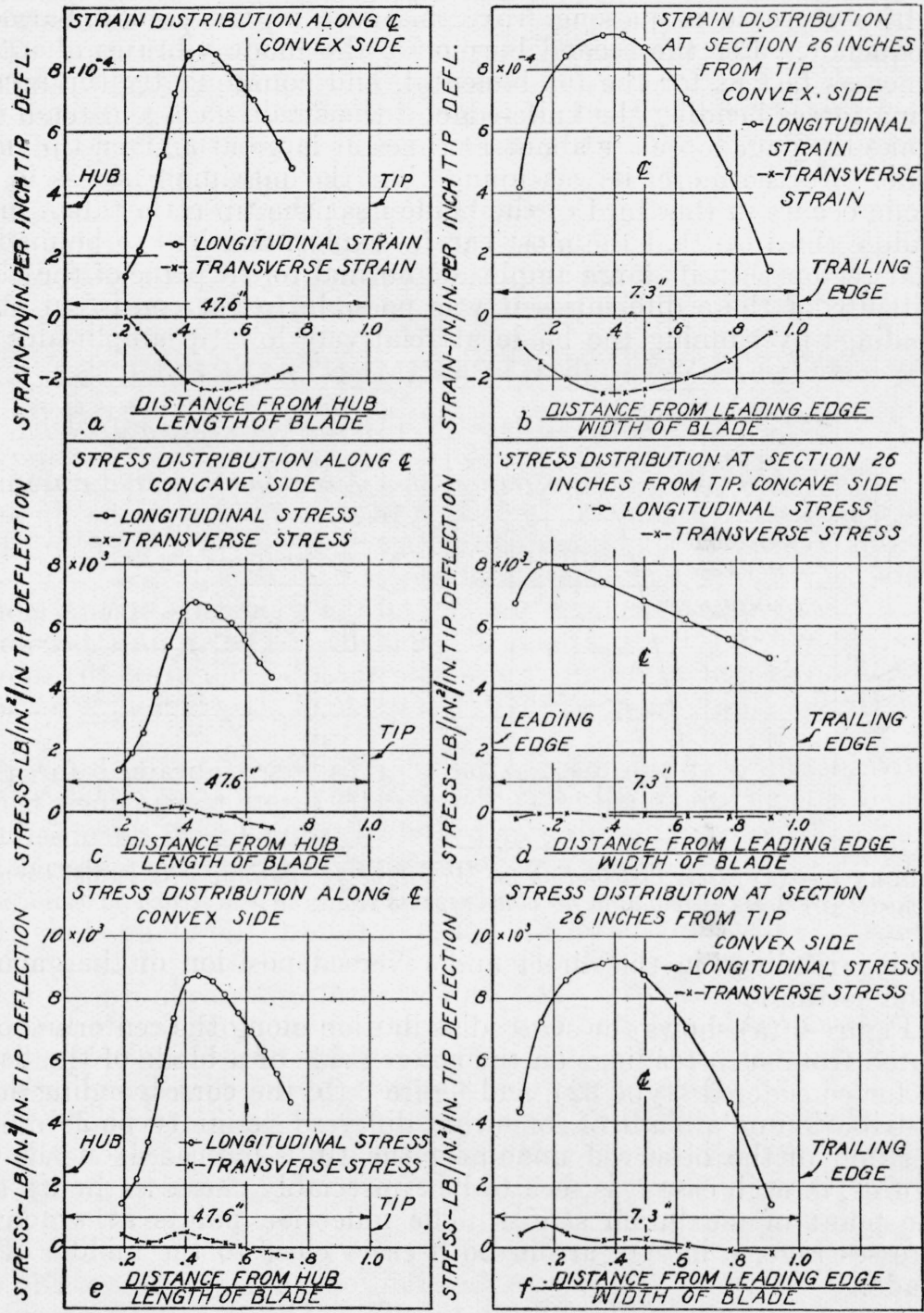

Figure 5.-Distribution of stress and strain at extreme fiber for duralumin blade type 32, vibrating with fundamental mode.

Figure 5 (f) shows the stress distribution on the convex side at a section 26 in. from the tip. The longitudinal stress is higher than on the concave side, corresponding to the greater distance to the extreme fiber. The transverse stress is no longer zero; this is not surprising since the convex side is not so nearly plane as the concave side. 


\section{STRESS DISTRIBUTION FOR SECOND HARMONIC MODE}

All the stress distributions described so far were observed in a blade vibrating with its fundamental frequency. The experimental difficulties increase in passing from this case to the second harmonic frequency. For the second harmonic, the blade vibrates about 3.7 times as fast as for the fundamental, and consequently the accelerating forces bending the knife-edge of the strain gage and tending to shake the gage loose are about 14 times as large at a given tip amplitude. Furthermore, it was found that the maximum stress in this mode occurs in the third of the blade near the tip rather than in the middle third, so that the most careful exploration had to be made in that region with its large amplitude normal to the plane of the blade. In spite of these difficulties it was possible to get consistent strain readings by running the blade at relatively low tip amplitudes and
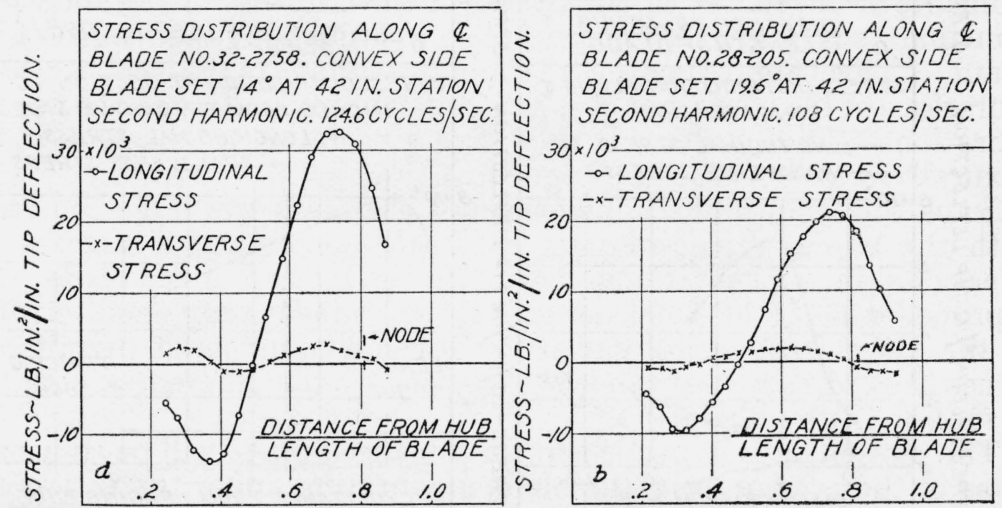

FIGURE 6.-(a) Stress distribution for blade type 32 vibrating with second harmonic mode; (b) stress distribution for blade type 28 vibrating with second harmonic mode.

taking readings in the direct and reversed position of the gage for each setting.

Figure 6 (a) shows the stress distribution along the centerline computed from such readings on the convex side of a blade of the design so far considered (type 32), and figure 6 (b) the corresponding stress distribution on a blade of somewhat different design (type 28). ${ }^{8}$ The position of the observed node near the tip is indicated on the two figures; in each case it is seen to be appreciably closer to the tip than the point of maximum stress. The inflection points at which the stresses reverse in sign are in both cases close to the middle of the blade.

\section{THEORETICAL ANALYSIS OF STRESS DISTRIBUTION IN A PROPELLER BLADE VIBRATING WITHOUT ROTA- TION}

It was deemed worth while as a check on both the technique used and the experimental results obtained to compare these results with those given by a theoretical analysis. Hansen and Mesmer $^{9}$ calcu-

\footnotetext{
8 The scatter of observed strain amplitudes plotted against tip amplitudes for this second blade was reduced by replacing the original Tuckerman gage by one of special design that was lightened as much as possible so as to minimize inertia forces.

Z. Flugtech. Motorluftschiffiahrt 24, 298 (1933).
} 
lated the stress distribution in a propeller blade vibrating without rotation by setting up the equation of motion of the blade, solving the equation for a natural mode, and from the mode calculating the stress at any point. A brief description of the analytical procedure used is given below.

\section{METHOD}

(a) EQUATION OF MOTION OF BLADE

The exact equations of motion of a beam with an unsymmetrical cross section whose area, moments of inertia, and principal axes of inertia vary along its length would be extremely complicated, even if they could be written down. For this reason it is customary ${ }^{10}$ to treat the problem by an approximate method, assuming that the motion of the blade is adequately represented by the motion of a beam with symmetrical cross sections, whose areas and principal moments of inertia are equal to those of the propeller blade, and whose principal axes of inertia remain parallel throughout the length of the beam. This approximate treatment cannot reproduce torsional vibrations of the blade, nor give any close approximation to the natural vibrations of high order. It does give a useful approximation to the flexural vibrations of lower frequency.

Since the longitudinal dimensions of the blade are large compared with the lateral dimensions, it is further customary to neglect the effect of shear and rotational inertia on the motion of the blade. For a propeller blade of usual design this introduces only small errors ${ }^{11}$ at the lower frequencies, and it is convenient in that it permits one to use the ordinary beam theory in setting up the differential equation of motion of the blade.

The motion of each particle in this idealized blade will be sinusoidal if, as in the present case, the blade is vibrating under the action of a sinusoidal exciting force or moment applied at the hub in a principal plane of inertia. One may then express the displacement at any section by eq 3:

$$
z=X \sin p t
$$

where $p / 2 \pi$ is the frequency of the exciting force or moment in cycles/second and $X$ is the amplitude of displacement at a distance $x$ from the center of the hub. One has a complete picture of the motion if both $X$ and $p$ are known.

The differential equation which $X$ must satisfy is obtained by substituting eq 3 in the equation:

$$
\frac{d^{2}}{d x^{2}}\left(E I \frac{d^{2} z}{d x^{2}}\right)=-\rho A \frac{d^{2} z}{d t^{2}}
$$

expressing the equilibrium of shear forces and inertia forces in a transverse direction; $E I$ denotes the flexural rigidity of the section of the blade considered and $\rho A$ the mass per unit length at that same section. Inserting eq 3 in eq 4 yields:

$$
\frac{d^{2}}{d x^{2}}\left(E I \frac{d^{2} X}{d x^{2}}\right)=\rho A p^{2} X
$$

\footnotetext{
10 See for instance Griffith. Advisory Comm. Aeronaut. (Gt. Brit.) R. \& M. no. 451 (1918).

11 S. Timoshenko Vibration Problems in Engineering, p. 231. (D .Van Nostrand Co., New York, 1928.)
} 
The solution of this differential equation is simple in the case of a beam in which both the coefficients $E I$ and $A$ are constant. But in the case of a propeller these coefficients are not even approximately constant. This is brought out clearly by the curves of figure 7 (a) and 7 (b), respectively, which show the distribution of $\frac{\sqrt{A}}{L}$ and $\frac{\sqrt[4]{I}}{L}$ plotted against the relative distance $x / L$ from the center of the hub for blade 32-2758; this blade is of the same design (type 32) as blade 32-2762. Both quantities decrease rapidly from the hub to the tip; $A$ and $I$ will decrease even more rapidly since they are proportional to the square and the fourth power of these quantities, respectively. The distribution of both $A$ and $I$ was obtained from direct measurements of the section of the blade at 15 sections along its length of $47.6 \mathrm{in}$.

Neither $A$ nor $I$ vary with $x$ in a simple way. There seemed little hope, therefore, of obtaining for them an analytical expression that
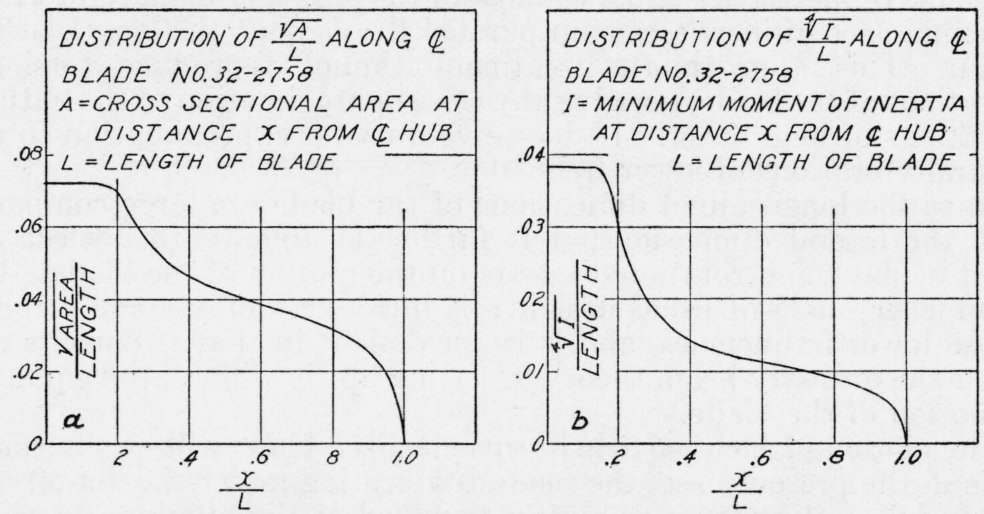

Figure 7.-Variation of cross-sectional area (a), and of moment of inertia (b) along blade.

would give to the differential eq 5 an integrable form. Hence, it was decided to make use of the numerical method of solution that has been applied to a number of propellers by Hansen and Mesmer ${ }^{12}$; it is the mathematical counterpart of a well-established graphical method for the computation of natural modes and frequencies of rotating shafts of varying section..$^{13}$

The formula used by Hansen and Mesmer ${ }^{14}$ to compute $X$ and $p$ for the vibration of a bar may be derived as follows:

Replace the independent variable $x$ by the ratio:

$$
\xi=\frac{x}{L}
$$

so that eq 5 takes on the form:

$$
\frac{d^{2}}{d \xi^{2}}\left(\frac{I}{L^{4}} \frac{d^{2} X}{d \xi^{2}}\right)=\rho \frac{p^{2} L^{2}}{E} \frac{A}{L^{2}} X
$$

where $I / L^{4}$ and $A / L^{2}$ are both known functions of $\xi$ and where $\xi$ varies from 0 to 1 as one passes from the point of clamping to the tip of the blade.

12 Z. Flugtech. Motorluftschiffahrt, 24, 298 (1933).

13 S. Timoshenko. Vibration Problems in Engineering, p. 231 (D. Van Nostrand Co., New York, 1928).

14 Hansen and Mesmer limited their discussion to a clamped-free bar. 
$X$ is a function of $\xi$ alone independent of the time $t$, of the form

$$
\frac{X}{d}=f(\xi)
$$

where $d$ is the amplitude of displacement at the tip of the blade $(\xi=1)$. For each value of $p, f(\xi)$ is a definite function of $\xi$ depending only on the type (force or moment) and the frequency of the excitation, the dimensions of the bar, and the end conditions.

The present work is concerned primarily with conditions of resonance. At resonance the exciting force or moment becomes negligible in comparison with the inertial reactions of the vibrating blade.

For the clamped-free bar one can, therefore, assume for the boundary conditions at the tip end $(\xi=1)$, zero shear, zero bending moment; at the hub end $(\xi=0)$, zero slope, zero deflection.

$$
\left.\begin{array}{c}
\frac{d}{d \xi}\left(\frac{I}{L^{4}} \frac{d^{2} X}{d \xi^{2}}\right)=0, \frac{I}{L^{4}} \frac{d^{2} X}{d \xi^{2}}=0, \text { at } \xi=1 \\
\frac{d X}{d \xi}=0, X=0, \text { at } \xi=0
\end{array}\right\}
$$

Any value of $X$ as a function of $\xi$ with the corresponding value of $p$, that satisfies both eq 7 and 8 represents a "natural" mode of vibration of the blade. An expression for $X(\xi)$ is obtained by integrating eq 7 four times in succession, determining each time the constant of integration from one of the four boundary conditions eq 8. This leads to the following integral equation for the natural mode of a clamped-free bar:

$$
X=\frac{\rho p^{2} L^{2}}{E} \int_{0}^{\xi} \int_{0}^{\xi L^{4}} \bar{I} \int_{1}^{\xi} \int_{1}^{\xi} \frac{A}{L^{2}} X d \xi d \xi d \xi d \xi
$$

(b) NUMERICAL SOLUTION OF EQUATIONS OF MOTION

The final deflection curve $X(\xi)$ on the left of eq 9 must have the same shape as the assumed deflection curve $X(\xi)$ in the integrand on the right if the latter describes a possible mode of vibration of the blade. To test this condition in a given case one must compute two double integrals of the type:

$$
\left.\begin{array}{rl}
F & =\int_{1}^{\xi} \int_{1}^{\xi} \varphi(\xi) d \xi d \xi \\
G & =\int_{0}^{\xi} \int_{0}^{\xi} \psi(\xi) d \xi d \xi
\end{array}\right\}
$$

where $\varphi(\xi), \psi(\xi)$ are known functions of $\xi$; in this particular case they are:

$$
\varphi(\xi)=\frac{A}{L^{2}} X, \psi(\xi)=\frac{L^{4}}{I} F
$$

$F$ may be converted into the form $G$ by replacing $\xi$ by $1-\xi$, so that only the second form $(G)$ need be considered. Hansen and Mesmer ${ }^{15}$ use a convenient method for integrating this second form numerically. It consists in subdividing the interval from $\xi=0$ to $\xi=1$ into $n$ equal

${ }^{15} \mathrm{Z}$. Flugtech. Motorluftschiffahrt 24, 298 (1933). 
intervals of width $h=1 / n$ and tabulating the values of $\psi(\xi)$ for the boundaries of these intervals:

$$
\psi(0), \psi\left(\frac{1}{n}\right), \psi\left(\frac{2}{n}\right), \ldots, \psi\left(\frac{i}{n}\right), \psi\left(\frac{i+1}{n}\right), \ldots,
$$

The interval spacing $h$ is chosen small enough so that the integrand $\psi(\xi)$ in the interval $\frac{i}{n} \leq \xi \leq \frac{i+2}{n}(i=0,1,2, \ldots, n-2)$ may be represented accurately by a parabola:

$$
\psi(\xi)=c_{0 i}+c_{1 i} \xi+c_{2 i} \xi^{2}
$$

The 3 constants of this parabola are then determined from the condition that $\psi(\xi)$ must go through the 3 points $\psi\left(\frac{i}{n}\right), \psi\left(\frac{i+1}{n}\right), \psi\left(\frac{i+2}{n}\right)$.

The value of $G(\xi)$ at any interval may now be found by substituting eq 11 in eq 10 and integrating twice with respect to $\xi$. This leads to the following formulas:

$$
\left.\begin{array}{l}
G_{0}=0 \\
G_{1}=\frac{1}{12 n^{2}}\left(3.5 \psi_{0}+3 \psi_{1}-0.5 \psi_{2}\right) \\
G_{i}=2 G_{i-1}-G_{i-2}+\frac{1}{12 n^{2}}\left(\psi_{i-2}+10 \psi_{i-1}+\psi_{i}\right)
\end{array}\right\}
$$

where $G_{0}$ and $\psi_{0}$ denote values of $G(\xi)$ and $\psi(\xi)$ at the origin $(\xi=0)$ and $G_{i}$ and $\psi_{i}$ values of the same quantities at the end of the $i$-th interval $\left(\xi=\frac{i}{n}\right) . \quad F(\xi)$ can be computed in the same way, remembering only that the direction of integration must be reversed. This leads to the formulas:

$$
\left.\begin{array}{rl}
F_{n} & =0 \\
F_{n-1} & =\frac{1}{12 n^{2}}\left(3.5 \varphi_{n}+3 \varphi_{n-1}-0.5 \varphi_{n-2}\right) \\
F_{i} & =2 F_{i+1}-F_{i+2}+\frac{1}{12 n^{2}}\left(\varphi_{i+2}+10 \varphi_{i+1}+\varphi_{i}\right)
\end{array}\right\}
$$

where $F_{i}$ and $\varphi_{i}$ denote values of $F(\xi)$ and $\varphi(\xi)$ at the end of the $i$-th interval $\left(\xi=\frac{i}{n}\right)$.

In the present work it was found convenient to subdivide the length of the blade into 20 equal intervals, thus choosing $n=20$. Table 1 illustrates a convenient arrangement for computing all values of $F$ and $G$ except $F_{\mathrm{n}-1}$ and $G_{1}$, which were computed directly from the second formulas of eq 12 and eq 13 . The table was taken from the computation of the fundamental mode of a blade of type 32 vibrating as a clamped-free bar. Part A shows the computation of the integral $F_{0}$, choosing for the mode $X=X_{0}$ values that are proportional to the deflection curve of the blade under its own weight. $\varphi_{i}$ and $F_{i}$ denote values of $\varphi=\frac{A X_{0}}{L^{2}}$ and $F$ at the end of the $i$-th interval. 
Part B of the table is carried out the second double integration, namely, that leading to $G$ as given by eq $10 ; \frac{L^{4} F}{I}$ is substituted for $\psi(\xi)$, where $F$ is taken from the previous table. In the last row of part B is the value of $G$ at the end of each interval. It is, sccording to eq 9 , proportional to the mode $X_{1}$ corresponding to an inertia loading produced by the assumed mode $X_{0}$. The ratio $X_{0} / G_{0}$, as shown in a separate row below the tables, ranges from $2.12 \times 10^{-3}$ to $3.56 \times 10^{-3}$. This shows that the eq 9 is far from being satisfied. A closer degree of proportionality will be obtained if the process is now repeated starting with a mode proportional to $X_{1}$ (which is proportional to $G_{0}$ ) and leading to a mode $X_{2}$ proportional to the distribution $G_{1}(\xi)$ obtained in this second calculation. The ratio $X_{m+1} / G_{m}$ may be made constant to any degree of accuracy, provided the procedure is repeated a sufficient number of times. In the present work constancy within slide rule error was considered sufficient. 
TABLE 1.-First approximation in computation of fundamental mode duralumin blade, type 32.

A. Computation of $\frac{E}{\rho p^{2} L^{2}} X_{1}=\int_{0}^{\xi} \int_{0}^{\xi} \frac{L^{4}}{I} \int_{1}^{\xi} \int_{1}^{\xi} \frac{A}{L^{2}} X_{0} d \xi d \xi d \xi d \xi$

$$
F_{0}(\xi)=\int_{1}^{\xi} \int_{1}^{\xi} \frac{A}{L^{2}} X_{0} d \xi d \xi=\int_{1}^{\xi} \int_{1}^{\xi} \varphi d \xi d \xi
$$

Computation begins at the right column and proceeds toward the left.

\begin{tabular}{|c|c|c|c|c|c|c|c|c|}
\hline (a) $i_{\ldots}$ & $\begin{array}{l}0 . \\
0 .\end{array}$ & $\begin{array}{l}* * * * \\
* * * *\end{array}$ & $\begin{array}{l}0.20 \\
4 .\end{array}$ & $\begin{array}{l}* * * * \\
* * * *\end{array}$ & $\begin{array}{l}0.85 \\
17 .\end{array}$ & $\begin{array}{l}0.90 \\
18 .\end{array}$ & $\begin{array}{l}0.95 \\
19 .\end{array}$ & $\begin{array}{l}1.00 \\
20 .\end{array}$ \\
\hline (b) $X_{0} \ldots \ldots$ & 0.0000 & $* * * *$ & 4. 787 & $* * * *$ & 627.2 & 720.5 & 814.2 & 908.0 \\
\hline (c) $\varphi_{i}=\frac{A}{L^{2}} \cdot X_{0 \ldots} \ldots \ldots$ & +0.0000 & $* * * *$ & +0.0233 & $* * * *$ & +0.5332 & +0.4756 & +0.3257 & 0.0 \\
\hline $\begin{array}{l}\text { (d) } 10 \varphi_{i+1} \\
\text { (e) } \varphi_{i+2} \\
\text { (f) } 2 \cdot 12 n^{2} F_{i+1} \\
\text { (g) (c) }+ \text { (d) }+(\mathrm{e})+(\mathrm{f}) \\
\text { (h) } 12 n^{2} F_{i+2}\end{array}$ & $\begin{array}{r}+.0105 \\
+.0059 \\
+1399.0000 \\
+1399.0000 \\
647.0000 \\
\end{array}$ & $\begin{array}{l}* * * * \\
* * * * \\
* * * * \\
* * * * \\
* * * *\end{array}$ & $\begin{array}{r}+.2961 \\
+.0377 \\
+981.2000 \\
+981.5000 \\
439.0000 \\
\end{array}$ & $\begin{array}{l}* * * * \\
* * * * \\
* * * * \\
* * * * \\
* * * *\end{array}$ & $\begin{array}{r}+4.7560 \\
+.3257 \\
+10.4200 \\
+16.0400 \\
\end{array}$ & $\begin{array}{r}+3.2570 \\
+1.47900 \\
+5.2120 \\
0.0000 \\
\end{array}$ & 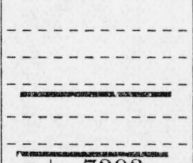 & 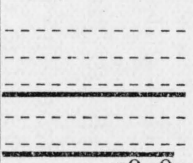 \\
\hline (i) $(\mathrm{g})-(\mathrm{h})=12 n^{2} F_{i} \ldots \ldots$ & +752.0000 & $* * * *$ & 7542.5000 & $* * * *$ & $\overline{+15.3000}$ & 75.2120 & $a+.7393$ & ${ }^{a} 0.0$ \\
\hline (j) $\frac{(\imath)}{12 n^{2}}=F_{i}=F_{0}(\xi) \ldots$ & 0.1566 & $* * * *$ & 0.1131 & $* * * *$ & 0.00319 & 0.001086 & 0.000154 & 0.0 \\
\hline
\end{tabular}

a Computed by first and second parts of equations 13 . 
B. Computation of $G_{0}(\xi)=\int_{0}^{\xi} \int_{0}^{\xi} F^{0} \frac{I}{L^{4}} d \xi d \xi=\int_{0}^{\xi} \int_{0}^{\xi} \psi d \xi d \xi$

Computation begins at the left column and proceeds toward the right.

\begin{tabular}{|c|c|c|c|c|c|c|c|c|}
\hline (a) $i_{-}$ & $\begin{array}{l}0 . \\
0 .\end{array}$ & $\begin{array}{l}0.05 \\
1 .\end{array}$ & $\begin{array}{l}0.10 \\
2 .\end{array}$ & $\begin{array}{l}0.15 \\
3 .\end{array}$ & $\begin{array}{l}0.20 * \\
4 .\end{array}$ & $\begin{array}{llll}* & * & * & * \\
* & * & * & *\end{array}$ & $\begin{array}{l}0.95 \\
19 .\end{array}$ & $\begin{array}{l}1.00 \\
20 .\end{array}$ \\
\hline $\begin{array}{l}\text { (c) } \psi i=F_{o}(\xi) \cdot \frac{I}{L^{4}} \\
\text { (d) } 10 \psi_{i-1} \\
\text { (e) } \psi_{i-2} \\
\text { (f) } 2 \cdot 12 n^{2} G_{i-1} \\
\text { (g) (c) }+(\mathrm{d})+(\mathrm{e})+(\mathrm{f}) \\
\text { (h) } 12 n^{2} G_{i-2} \\
\text { (i) (g) }(\mathrm{h})=12 n^{2} G_{i} \\
\text { (j) } \frac{(\mathrm{i})}{12 n^{2}}=G_{i}=G_{0}(\xi) \\
\quad \frac{X_{o}}{G_{o}}\end{array}$ & $\begin{array}{r}+73300 . \\
-0 . \\
0 .\end{array}$ & $\begin{array}{c}+68100 . \\
-1 .+\cdots \\
+429300 . \\
+89.4 \\
2.26 \cdot 10^{-3}\end{array}$ & $\begin{array}{r}+63100 \\
+681000 \\
+73300 \\
+858600 \\
1676000 \\
000 \\
+1676000 \\
+349.1 \\
3.24 \cdot 10^{-3}\end{array}$ & $\begin{array}{r}+58500 \\
+631000 \\
+68100 \\
+3352000 \\
+4110000 \\
429300 \\
+3681000 \\
+767 \\
3.49 \cdot 10^{-3}\end{array}$ & $\begin{array}{r}+117800 \\
+585000 \\
+63100 \\
+7362000 \\
+8128000 \\
1676000 \\
+6452000 \\
+1344 \\
3.56 \cdot 10^{-3}\end{array}$ & $\begin{array}{l}* * * * \\
* * * * \\
* * * * \\
* * * * \\
* * * * \\
* * * * \\
* * * * \\
* * * * \\
* * * *\end{array}$ & $\begin{array}{r}+118000 \\
+3880000 \\
+709000 \\
+3186000000 \\
+3191000000 \\
1367000000 \\
+1824000000 \\
+380000 \\
2.14 \cdot 10^{-3}\end{array}$ & $\begin{array}{r}0 \\
+118000 \\
+38800 \\
+364800000 \\
+365000000 \\
159300000 \\
+205700000 \\
+428500 \\
2.12 \cdot 10^{-3}\end{array}$ \\
\hline
\end{tabular}

a Computed by first and second parts of equations 12 .

NotE.-In this type of integration it is sometimes necessary to carry intermediate steps to more significant figures than are retained in the result. To maintain the alignment of the columns zeros are written beyond the figures retained. 
Assume that $m$ computations were required to satisfy this criterion. Equation 9 may then be written as

$$
X_{m+1}(\xi)=\frac{\rho p^{2} L^{2} G_{m}}{E}=X_{m}(\xi)
$$

Solve this for the natural frequency $f$ corresponding to this mode:

$$
f=\frac{p}{2 \pi}=\frac{1}{2 \pi L} \sqrt{\frac{E}{\rho}} \sqrt{\frac{X_{m}}{G_{m}}}
$$

(c) CALCULATION OF STRESS

Knowing the mode, the stress distribution can be computed, provided the transverse stresses are negligible. In that case the longitudinal stresses are:

$$
\sigma_{x}=E \epsilon_{x}=E c \frac{d^{2} X}{d x^{2}}=\frac{E c}{L^{2}} \frac{d^{2} X}{d \xi^{2}}
$$

where $c$ is the distance from the neutral axis to the extreme fiber-
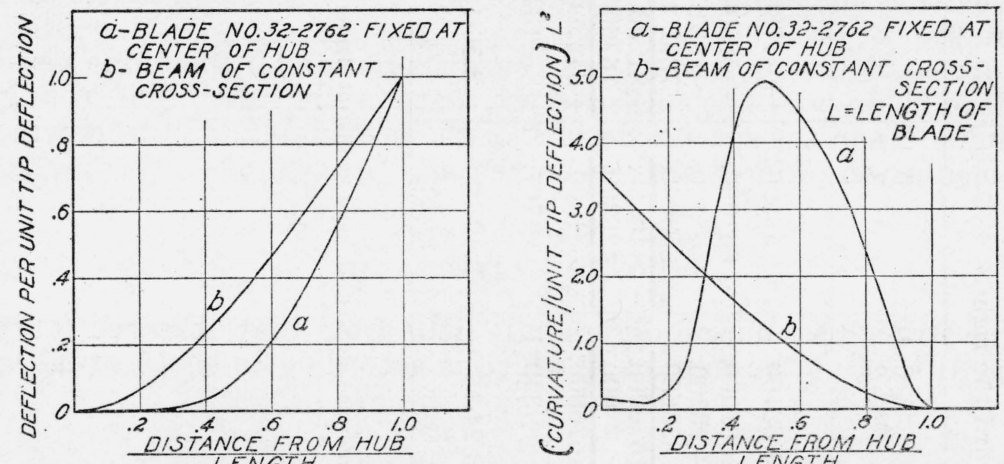

Figure 8.-Fundamental mode and curvature.

Or, if $d$ is the deflection at the tip, the stress amplitude per unit tip deflection becomes:

$$
\frac{\sigma_{x}}{d}=\frac{E c}{L^{2} d} \frac{d^{2} X}{d \xi^{2}}
$$

The neglect of transverse stresses in this analysis is probably justified in first approximation; the experimental data show that the transverse stresses are small compared with the longitudinal stresses in the region of maximum stress (see fig. 5, 6). A more exact calculation of the stresses would require a knowledge of $\epsilon_{y}$ as well as $\epsilon_{x}$ which is proportional to the curvature of the mode. This involves a complete solution of the deformation of a solid of variable section under the action of distributed loads. It was thought not worth while to attempt such a solution in view of the extra work involved and the small correction which would result from it. 


\section{FUNDAMENTAL MODE OF FIXED-FREE PROPELLER BLADE}

Curve a, figure 8 (left diagram) shows the fundamental mode for a blade of type 32 computed by the method outlined above. The blade is assumed clamped at the center of the hub. The fundamental mode for a clamped-free bar of constant cross section with unit deflection at the $\operatorname{tip}^{16}$ is shown for comparison. The two curves differ considerably.

That difference is brought out much more emphatically by intercomparing the curvatures of the neutral fibers for these cases (fig. 8, right diagram). While the maximum curvature for the blade comes at the middle, that for the uniform bar occurs at the point of clamping. It is not safe, therefore; to conclude anything regarding the stresses in propeller blades from the stresses in uniform bars.

The stresses per unit tip deflection may be computed from the curvature by means of eq 17, provided the extreme fiber distance $c$ is known. The distribution of $c / L$ along the centerline for both the convex side and the concave side of a blade of type 32 is shown in figure 9 .

Curve a, figure 10, shows the stress distribution for the fundamental mode of blade type 32 clamped at the center of the hub. The Young's modulus $E$ and the specific density of the material (25ST) from which the blades were forged are here taken as

$$
\begin{aligned}
& E=10^{7} \mathrm{lb} / \text { in }^{2} \\
& \rho=2.59310^{-4} \mathrm{lb} \text {-mass } / \text { in }^{3}
\end{aligned}
$$

The stress distribution differs only little from that observed (curve c, fig. 10). But the frequency which is according to eq 15 equal to

$$
f=30.7 \text { cycles/second }
$$

is some 14 percent lower than that observed. This suggests that the point of fixity chosen in the computation should have been placed at a point some distance from the hub and toward the tip. This would shorten the effective length of the blade, and assuming that the blade behaved as a uniform beam in which the frequency is inversely proportional to the square of the length, would lead to a higher frequency. It was decided, therefore, to repeat the computation choosing a point of fixity 15 percent of the distance from the center of the hub to the tip of the blade. This is the point $(\xi=0.15)$ which corresponds roughly to the limit of the contact area between hub-clamp and blade. The resulting stress distribution is shown in curve b, figure 10. It is seen to differ only slightly from the stress distribution for clamping at the hub. The frequency becomes

$$
f=26.6 \text { cycles/second }
$$

which is a decrease although the effective length of the blade has been decreased. A more detailed investigation shows that this apparent anomaly is due to the rapid decrease in section near the root of the blade. This shows again the need for caution in drawing analogies between a beam of uniform section and one of variable section such as a propeller blade.

\footnotetext{
${ }^{10}$ Lord Rayleigh. Theory of Sound, par. 173 (Macmillan Co., New York, 1894).
} 


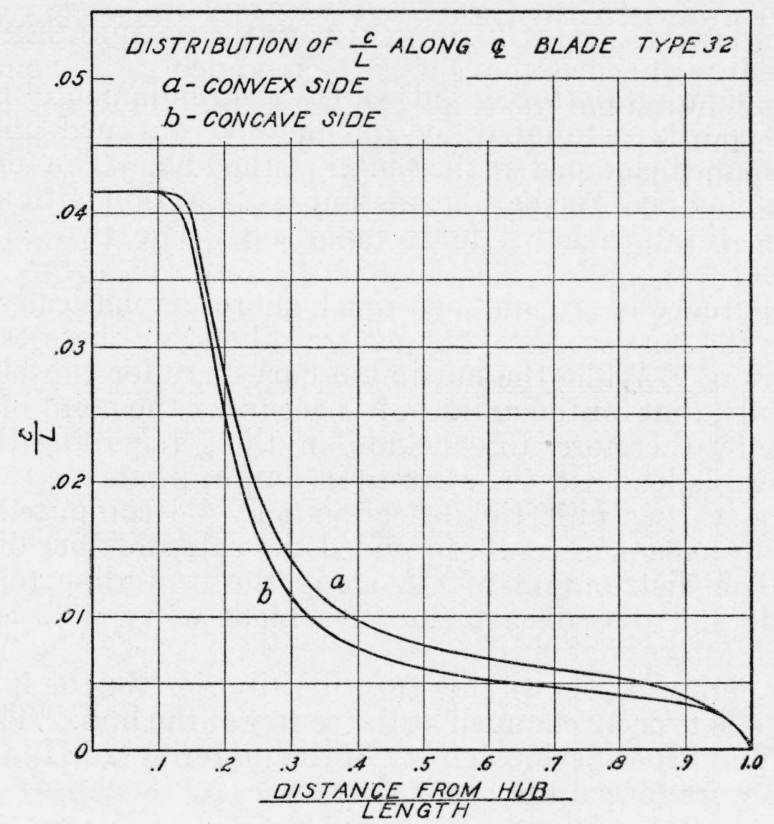

Figure 9.-Variation of distance (c) from neutral axis to extreme fiber along blade. ( $L$ length of blade)

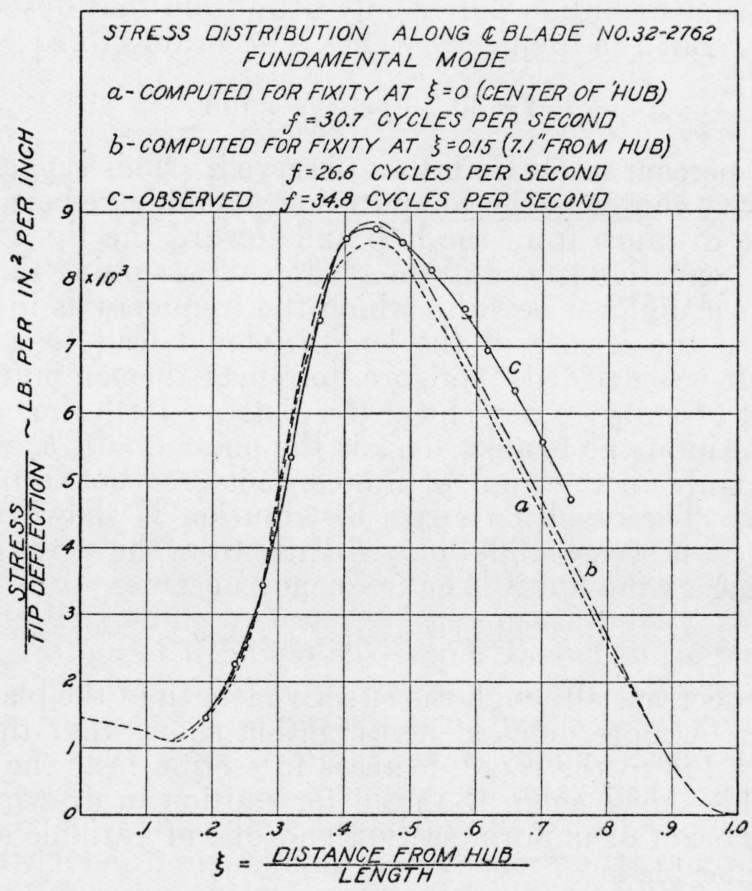

Figure 10.--Stress distribution, fundamental mode. 


\section{SECOND HARMONIC MODE OF FIXED-FREE PROPELLER BLADE}

The procedure outlined above must be modified in the computation of the second harmonic mode of the fixed-free blade. The correct mode must again satisfy the integral eq 9 . In addition it must have a node at a point near the tip of the propeller. Hansen and Mesmer arbitrarily assume the location of this node at a point one-fourth of the blade length in from the tip $(\xi=0.75)$ and then proceed to compute the mode for this nodal position by starting with a mode $X_{0}$ satisfying the end conditions at the tip and at the hub and also going through

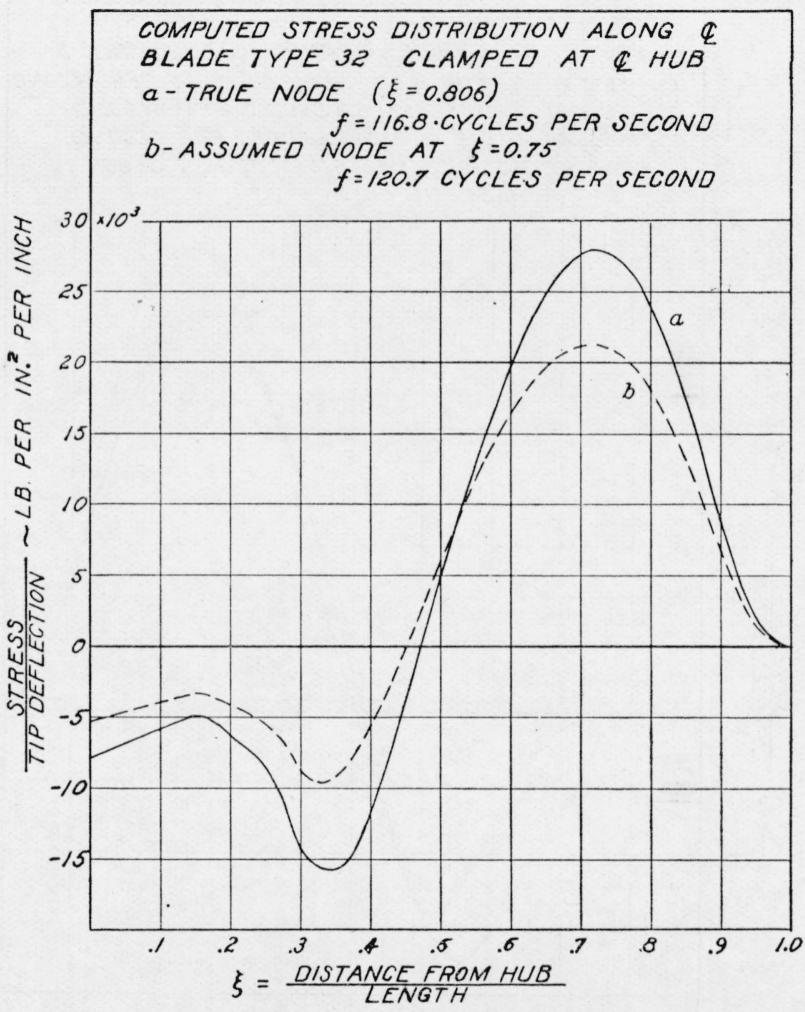

Figure 11.-Stress distribution, second harmonic mode.

zero at the assumed node. Using this value of $X_{0}$ they compute $X_{1}$ from eq 9. The mode $X_{1}$ will now, in general, have its node at a point some distance away from the assumed point $\xi=0.75$; to pull it back into this point Hansen and Mesmer add a mode proportional to the fundamental mode and choose the factor of proportionality such as to make the resultant mode go through 0 at $\xi=0.75$. If this procedure is repeated a few times the resultant mode will be proportional to the initial mode; Hansen and Mesmer then compute the frequency from their ratio as given by eq 15 . It is clear that the condition eq 9 of equality of initial and final mode is not satisfied by this method unless the proportion of fundamental mode to be added is equal to 0 . This suggested the following procedure for computing the true mode and correct position of the node. 
The ratio of the tip amplitude of the fundamental mode, added for compensation, to the amplitude of the second harmonic mode as computed by eq 9 is plotted for various positions of the node, say $\xi=$ $0.7,0.75,0.8$, and the nodal position for which this ratio is equal to 0 is obtained from these points by interpolation. Then the computation is repeated for the optimum location of the node to verify that the condition eq 9 actually holds within slide-rule error.

The frequency as computed by Hansen and Mesmer's method of forcing the node at $\xi=0.75$ practically agrees with that computed for

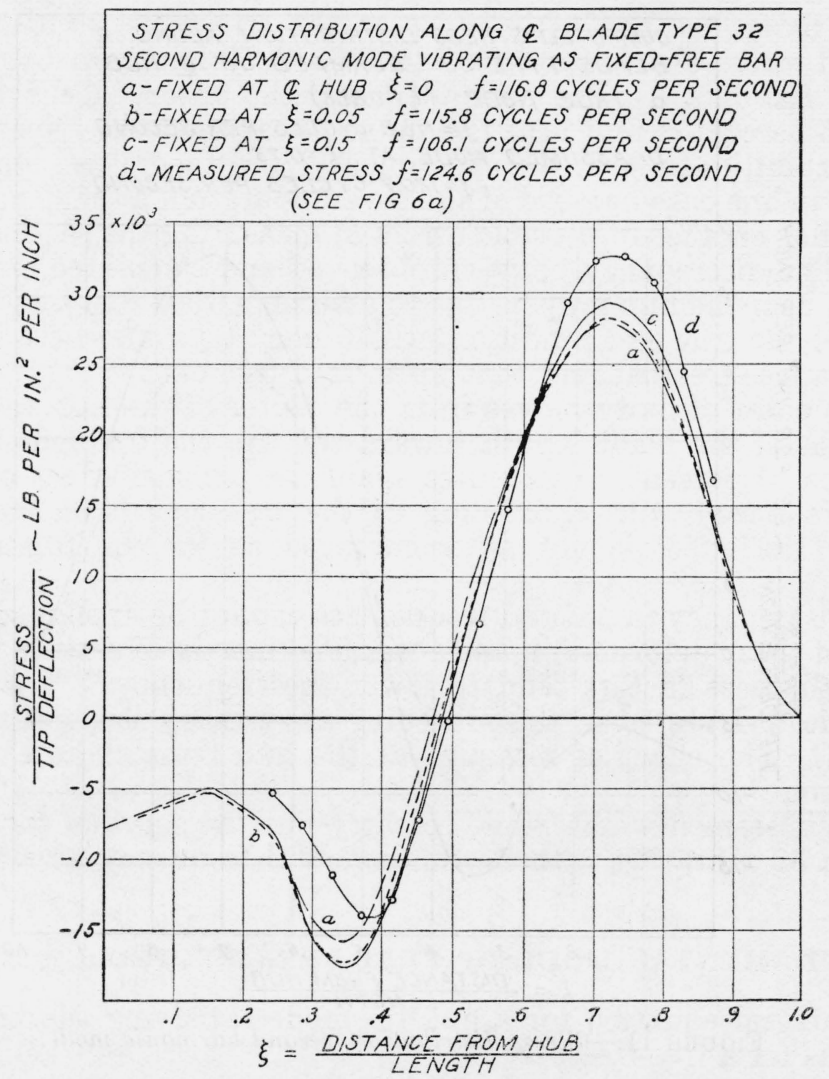

FIGURE 12.-Stress distribution, second harmonic mode.

the theoretically correct node, but the stress distribution so computed does not. This point is brought out in figure 11, which shows the stress distribution computed for blade 32-2762 fixed at the hub and vibrating in one case (curve a) with the theoretically correct mode having a node at $\xi=0.806$ and in the other (curve b) with the node at $\xi=0.75$ as assumed by Hansen and Mesmer. It is seen that the stress distributions for the two computations are similar in shape, but the stress per inch tip deflection for the correct node is some 20 to 30 percent higher than that for the node assumed at the $3 / 4$ point. The frequencies for these cases agree within 4 percent. It appears desirable, therefore, to find the solution of eq 9 whenever one is 
interested in the stress distribution as well as in the frequency of the second harmonic.

The frequency of the second harmonic mode assuming fixity at the center of the hub was calculated to be 116.8 cycles/second against an observed value of $124.6 \mathrm{cycles} / \mathrm{second}$. It was first thought that this divergence might be due to selecting the wrong point of fixity, and hence it was decided to compute the stress distribution and frequency for two other points, one with the blade clamped at $\xi=0.05$ ( 2.38 in. from the center of the hub) and the other with the blade clamped at $\xi=0.15$ (7.14 in. from the center of the hub). The results of these computations are shown in figure 12 . It is seen that the change in point of fixity has had little effect on the stress distribution. The measured stress distribution for blade $32-2758$ is shown by curve $\mathrm{d}$ (see also fig. 6 (a)). The computed and the observed curves agree within 15 percent except near the tip and near the hub. Near the tip the uncertainties in both the experimental and theoretical results are greatest, in one case because of the severe vibration at that point and in the other because of possible errors in measuring the section of the blade. The discrepancy between observed and calculated stress distribution near the hub may be due to assuming ideal fixity at the hub instead of the true end condition, which must be somewhere between that for a free-free bar and that for a fixed-free bar.

As the point of fixity moves from the center of the hub to a point 15 percent of the blade length toward the tip, the frequency is lowered some 10 percent. One notes again the unusual effect of lowering of frequency with shortening of the free length of the blade, although the effect is not as pronounced as for the fundamental mode.

This discrepancy in natural frequencies cannot be explained by the neglect of shear deformation and rotational inertia in setting up eq 9 , since both these factors tend to lower the frequency ${ }^{17}{ }^{18}$, while the frequencies calculated in the preceding are already lower than those observed. The effect of restraint at the hub remains as a possible explanation.

Hence it seemed worth while to carry out the solution for a blade of design 32 vibrating with its fundamental frequency as a free-free bar.

\section{FUNDAMENTAL MODE OF FREE-FREE PROPELLER BLADE}

The integral equation for a natural mode satisfying the boundary conditions for a free-free bar:

$$
\left.\begin{array}{l}
\frac{d}{d \xi}\left(\frac{I}{L^{4}} \frac{d^{2} X}{d \xi^{2}}\right)=0, \frac{I}{L^{4}}\left(\frac{d^{2} X}{d \xi^{2}}\right)=0, \text { at } \xi=1 \\
\frac{d X}{d \xi}=0, \frac{d}{d \xi}\left(\frac{I}{L^{4}} \frac{d^{2} X}{d \xi^{2}}\right)=0, \text { at } \xi=0
\end{array}\right\}
$$

may be found by integrating eq 7 four times with respect to $\xi$ and each time determining the constant of integration by one of the boundary conditions. The first three boundary conditions eq 18 are the same

${ }_{17}^{17}$ Lord Rayleigh. Theory of Sound, par. 186 (Macmillan, New York, 1894).

18 S. Timoshenko. Phil. Mag. 41, 744 (1921). 
as for the clamped-free bar eq 8. The integral expression for the slope $d X / d x$ will, therefore, be the same and that for the mode can differ by a constant only:

$$
X=X_{1}+c_{0}
$$

where $X_{1}$ is the expression on the right side of eq 9 and $c_{0}$ may be evaluated by substituting eq 19 in the integral equation for shearing force:

$$
\frac{d}{d \xi}\left(\frac{I}{L^{4}} \frac{d^{2} X}{d \xi^{2}}\right)=\frac{\rho p^{2} L^{2}}{E} \int_{1}^{\xi} \frac{A}{L^{2}} X d \xi
$$

and making the right side equal to 0 at $\xi=0$. Inserting the value of $c_{0}$ so obtained in eq 19 gives the following integral equation for the natural mode of a free-free bar:

$$
\begin{aligned}
& X=\frac{\rho p^{2} L^{2}}{E}\left(\int_{0}^{\xi} \int_{0}^{\xi} \frac{L^{4}}{I} \int_{1}^{\xi} \int_{1}^{\xi} \frac{A}{L^{2}} X d \xi d \xi d \xi d \xi-\right. \\
& \left.-\frac{1}{\int_{0}^{1} \frac{A}{L^{2}} d \xi} \int_{0}^{1} \frac{A}{L^{2}} \int_{0}^{\xi} \int_{0}^{\xi} \frac{L^{4}}{I} \int_{1}^{\xi} \int_{1}^{\xi} \frac{A}{L^{2}} X d \xi d \xi d \xi d \xi d \xi\right)
\end{aligned}
$$

The solution of the integral on the right of eq 21 involves double integrals of the form $G$ and $F$ given in eq 10 and in addition singie integrals of the form:

$$
H(\xi)=\int_{0}^{\xi} \chi(\xi) d \xi
$$

The integral $H$ may be evaluated numerically in a manner analogous to that used in solving $G, F$. One chooses an interval spacing $1 / n$ that is so close that the value of the integrand over any interval $\frac{i}{n} \geqq \xi \geqq \frac{i+2}{n}$ may be closely approximated by a parabola passing through the 3 points $\chi\left(\frac{i}{n}\right), \lambda\left(\frac{i+1}{n}\right), \lambda\left(\frac{i+2}{n}\right)$. The value $H(\xi)$ at the end of the first interval and that at the end of the $i$-th interval are then given by:

$$
\begin{aligned}
& H_{1}=\frac{1}{1-n}\left(5 \chi_{0}+8 \chi_{1}-\chi_{2}\right) \\
& H_{i}=H_{i-1}+\frac{1}{1 \_n}\left(-\chi_{i-2}+8 \chi_{i-1}+5 \chi_{i}\right)
\end{aligned}
$$

where $H_{i}$ and $\chi_{i}$ denote values of $H(\xi)$ and $\chi(\xi)$ at the end of the $i$-th interval $\left(\xi=\frac{i}{n}\right)$. The integration may be conveniently tabulated in a manner analogous to that shown in table 1 for the integration of $F(\xi)$ and $G(\xi)$.

The fundamental mode of a blade, design type 32 , vibrating as a free-free bar, was found from eq 21 with the help of such a tabulation using 20 intervals $(n=20)$, and then repeating the integration until the ratio $\frac{\rho p^{2} L^{2}}{E}$ in eq 21 assumed the same value at the end of each interval. 


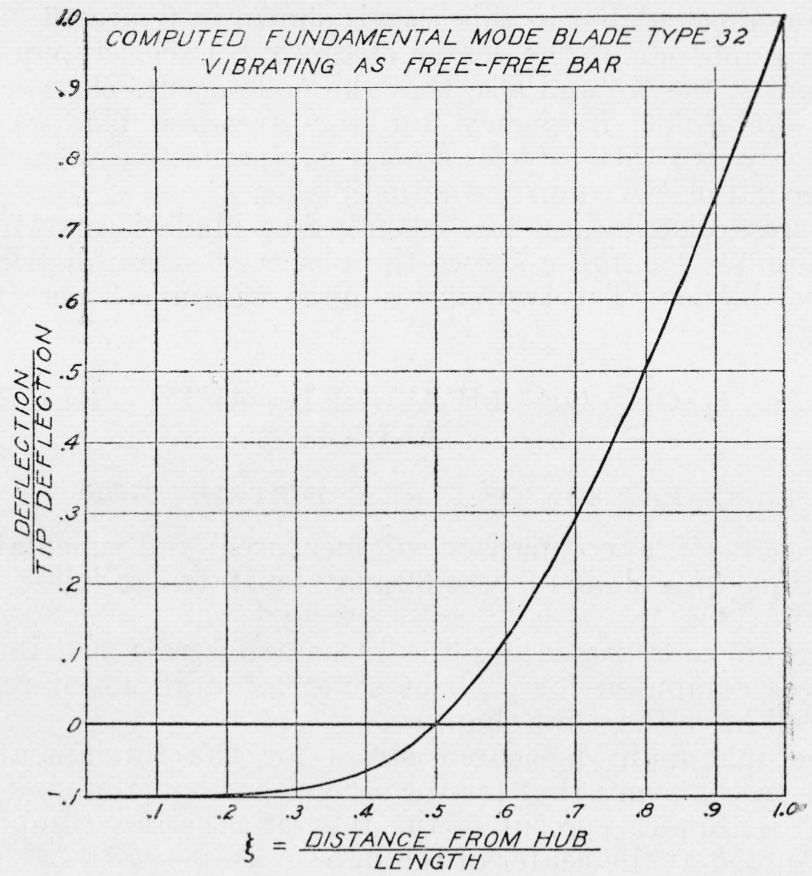

Figure 13.-Fundamental mode, blade vibrating as free-free bar:

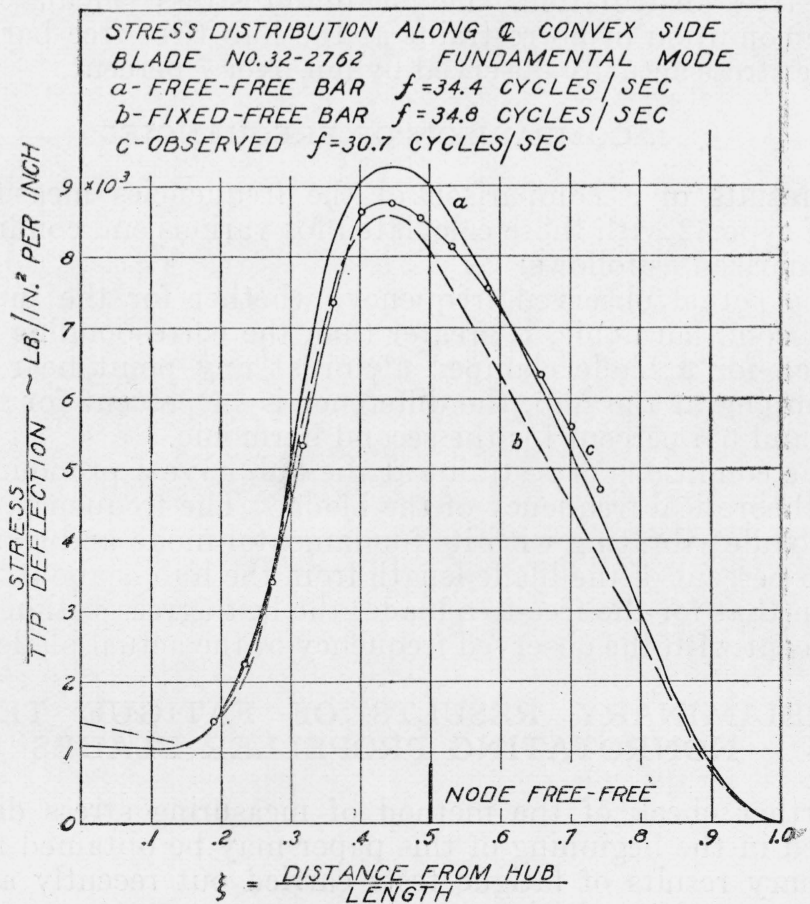

Figure 14.-Stress distribution, fundamental mode. 
The mode calculated in this way is shown in figure 13. It is seen that the amplitude at the center of the hub is closely equal to onetenth that at the tip and also that the node occurs close to the position $\xi=0.5$. The frequency for the free-free blade comes out theoretically as $f=34.4$ cycles/second compared to a value of $f=34.8$ cycles/second observed on the actual blade.

The stress distribution for the free-free blade is shown as curve $\mathrm{a}$ in figure 14. Curve $\mathrm{c}$ shows the observed stress distribution for the actual blade. The two curves agree within \pm 8 percent for the most part.

\section{COMPARISON OF MEASURED AND THEORETICAL VALUES}

\section{COMPARISON OF STRESS DISTRIBUTION}

The result of a comparison of measured and calculated stress distributions of a blade of type 32 may be stated as follows (see figs. 10,12 , and 14):

a. The curve representing the measured stress distribution and the curves computed for each of several conditions of restraint at the hub all have the same shape.

b. The maximum measured stress for the fundamental agrees within 3 percent, and that for the second harmonic mode (with node near tip) within 15 percent of the theoretical stress computed for a blade clamped at the center of the hub.

c. The conditions oi clamping have only slight effect on the theoretical stress distribution, the maximum stress calculated for the extreme condition of no restraint at the hub (free-free bar) differing from the stress actually observed by not over 7 percent.

\section{COMPARISON OF FREQUENCIES}

The results of a comparison of the frequencies measured for a blade of type 32 with those calculated for various end conditions may be summarized as follows:

a. The actual observed frequency, whether for the fundamental or the second harmonic, is greater than the corresponding frequency computed for a blade clamped at, or at any point near, the hub. For clamping at the hub, the difference is 14 percent for the fundamental and 6.5 percent for the second harmonic.

b. The conditions of restraint at the hub have a pronounced effect on the theoretical frequency of the blade. The frequency calculated for the blade vibrating with its fundamental mode and clamped at a point 15 percent of the blade lengtb from the hub is about 24 percent less than that for the free-free blade; the last agrees within a fraction of 1 percent with the observed frequency of the actual blade.

\section{PRELIMINARY RESULTS OF FATIGUE TESTS ON NONROTATING PROPELLER BLADES}

A further check of the method of measuring stress distribution described in the beginning of this paper may be obtained from some preliminary results of fatigue tests carried out recently at the $\mathrm{Na}$ tional Bureau of Standards. 
Eight propeller blades of various designs, forged from $25 \mathrm{ST}$ aluminum alloy, were vibrated at their fundamental mode, and explored with a strain gage. Two of the blades (nos. 43,903 and 43,904) were new, and the remaining six had been in service. Table 2 gives the magnitude and location of maximum strain.

TABLE 2.-Characteristics of aluminum alloy blades

\begin{tabular}{|c|c|c|c|c|}
\hline Blade number ${ }^{1}$ & $\begin{array}{l}\text { Blade } \\
\text { length }\end{array}$ & Frequency ${ }^{2}$ & $\begin{array}{l}\text { Maximum } \\
\text { longitudinal } \\
\text { strain ampli- } \\
\text { tude for 1-in. } \\
\text { tip amplitude }\end{array}$ & $\begin{array}{l}\text { Distance of } \\
\text { point of maxi- } \\
\text { mum strain } \\
\text { from tip }\end{array}$ \\
\hline $\begin{array}{l}33,155(4) \\
25,460(1) \\
25,363(099) \\
25,099(363 \text { and } 377) \\
43,904(3) \\
43,903(4 \text { and } 26,681) \\
25,626 \text { (7) } \\
27,056 \text { (7) }\end{array}$ & $\begin{array}{l}\text { in. } \\
48 \\
48 \\
481 / 2 \\
48 \\
48 \\
48 \\
461 / 2 \\
491 / 2\end{array}$ & $\begin{array}{r}\text { Cycles/second } \\
31.7 \\
33.1 \\
32.5 \\
32.6 \\
33.8 \\
33.8 \\
36.0 \\
30.7\end{array}$ & $\begin{array}{r}10^{-4} \text { in. } \\
7.30 \\
6.75 \\
6.25 \\
6.76 \\
6.55 \\
7.10 \\
7.80 \\
3(6.25)\end{array}$ & in. $\begin{array}{l} \\
281 / 2 \\
241 / 2 \\
24 \\
24 \\
24 \\
223 / 4 \\
291 / 2 \\
31\end{array}$ \\
\hline
\end{tabular}

1 The last digit, or digits, of the number identifying the second blade of the propeller are enclosed in parentheses. In two cases the second blade was changed during test.

2 All frequencies on $15 \mathrm{hp}$ motor. Frequency of 33,155 on $71 / 2 \mathrm{hp}$ motor was 32.4 .

3 Measured on blade 27,057 only.

4 New blade.

The blades were then subjected to high alternating bending stresses by increasing the armature current of the motor, M, (figs. 1, 2) until the tip amplitude reached a value corresponding to the desired stress amplitude. For the first two propellers tested, the stress amplitude had been chosen as 12,700 and $15,400 \mathrm{lb} /$ in. $^{2}$, values which proved to be too small to produce fatigue failure after more than a million cycles. The tip amplitudes at which these two blades were run were, therefore, raised to values corresponding to a maximum stress of 24,100 and $19,900 \mathrm{lb} /$ in. $^{2}$, respectively. The blades failed at these stresses after about two hours running for the first propeller and less than 20 minutes for the second propeller. The remaining six blades were run at one stress only (see table 3 ). The final fracture was preceded in every case by the formation of a typical fatigue crack across the blade at a section in the middle third where the stress differed only a few percent from the measured maximum stress.

TABLE 3.-Data on fatigue failures of aluminum alloy blades

\begin{tabular}{|c|c|c|c|c|}
\hline Blade number & $\begin{array}{l}\text { Maximum } \\
\text { stress }\end{array}$ & $\begin{array}{l}\text { Number of } \\
\text { cycles }\end{array}$ & $\begin{array}{l}\text { Distance } \\
\text { of crack } \\
\text { from tip }\end{array}$ & $\begin{array}{c}\text { Stress at } \\
\text { crack }\end{array}$ \\
\hline 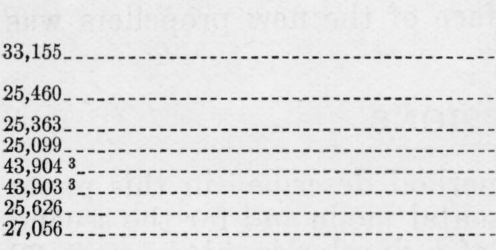 & $\left\{\begin{array}{c}1 \mathrm{~b} / \mathrm{in}^{2} \\
12,700 \text { for } \\
24,100 \text { for } \\
15,400 \text { for } \\
19,900 \text { for } \\
16,700 \\
14,500 \\
17,500 \\
16,600 \\
21,400 \\
18,800\end{array}\right.$ & $\begin{array}{r}1,350,000 \\
214,000 \\
2,140,000 \\
33,800 \\
505,000 \\
442,000 \\
2,060,000 \\
2,390,000 \\
233,000 \\
379,000\end{array}$ & \begin{tabular}{|c|} 
in. \\
$193 / 4,201 / 2,21$ \\
$241 / 2$ \\
23 \\
$271 / 2$ \\
29 \\
$241 / 2$ \\
$271 / 2$
\end{tabular} & $\begin{array}{r}\text { lb/in. }{ }^{2} \\
123,000 \\
219,700 \\
15,500 \\
14,000 \\
17,200 \\
16,100 \\
19,500 \\
18,100\end{array}$ \\
\hline
\end{tabular}

1 In the preceding run the stress at this point was only $12,200 \mathrm{lb} / \mathrm{in} .^{2}$

${ }^{2}$ In the preceding run the stress at this point was only $15,300 \mathrm{lb} / \mathrm{in} .^{2}$

3 New blade. 
The number of cycles to failure are plotted against maximum stress on the S-N diagram of figure 15. This same figure shows for comparison one S-N diagram (for strips of 25ST material) obtained by Briggs and Murphy in an air-driven high-speed fatigue machine at the National Bureau of Standards and one (for rotating cantilever beam specimens of the same alloy) obtained by D. J. McAdam, Jr. ${ }^{19}$ Finally it shows the S-N diagram for fatigue tests on specimens cut from a $25 \mathrm{ST}$ propeller blade. ${ }^{20}$ The eight points for the failure of fullsize blades fall, for the most part, below the $\mathrm{S}-\mathrm{N}$ diagrams for polished specimens. The points scatter considerably, and are too few in number to give a reliable value for the fatigue limit of a full-size blade. Much of the observed scatter may be due to differences in surface

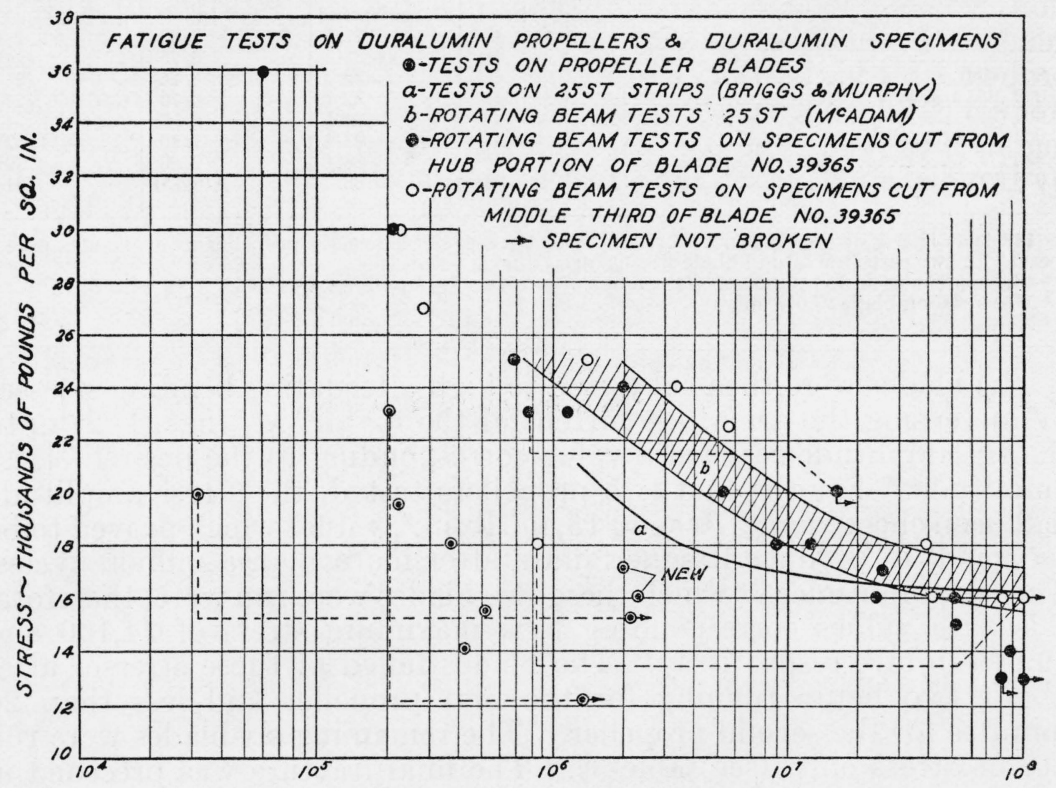

CYCLES OF STRESS FOR FAILURE

FigURE 15.-Results of fatigue tests on duralumin propellers and duralumin specimens.

condition of the blades. It will be seen that the new blades tested under the same conditions as the used blades withstood a greater number of alternations before failure. One failure on a used blade (no. 25,460) was noticed in the earliest stages and the crack was observed to follow a tortuous curve from one small pit in the surface to another. The highly polished surface of the new propellers was relatively free from irregularities.

\section{CONCLUSIONS}

1. By means of the experimental method described in this paper the stress distribution for the fundamental mode and for the second harmonic mode (with node near tip) of a duralumin blade type 32

10 Pamphlet no. 1,537-D, issued with Mining and Metallurgy (Feb. 1926).

${ }_{20}$ These tests were made by W. H. Swanger and R. D. France of this Bureau. 
can be determined; in the region of maximum stress it agrees within 12 percent with the computed distribution.

2. The theoretical stresses for the fundamental mode are, within 10 percent, independent of the restraint at the hub.

3 . The frequency is much more sensitive to the restraint at the hub than the stress distribution. It changed by some 26 percent for a change in restraint that produced a variation of only 10 percent in maximum stress for the fundamental.

4. Artificially produced fatigue failures on eight propeller blades occurred in each case at a point where the stress was within 10 percent of the maximum stress measured on the blade.

The third of these conclusions emphasizes the fact that computation, while giving good approximations for the stresses, is not, in general, a reliable means for determining the natural frequencies of a propeller blade; it is safer to rely on direct measurements of resonant frequencies insofar as they are obtainable. One step towards obtaining such measurements is the propeller-vibration indicator developed by Dryden and Tuckerman ${ }^{21}$ in connection with this research program.

Washington, December 18, 1934.

${ }_{21}$ BS J. Research 12, 537 (1934) RP678. 